\title{
Dispersion for Infusion Dosage Form
}

National Cancer Institute

\section{Source}

National Cancer Institute. Dispersion for Infusion Dosage Form. NCI Thesaurus. Code C149440.

Liquid sterile preparation consisting of two or more phases of which at least one is dispersed in the liquid phase, intended to be introduced, usually in large volumes, usually into the circulating blood stream. 